\title{
SEISMIC PERFORMANCE OF ANCIENT MASONRY BUILDINGS: A SENSITIVITY ANALYSIS
}

\author{
Nuno Mendes ${ }^{1}$, Paulo B. Lourenço ${ }^{1}$ \\ ${ }^{1}$ ISISE, Department of Civil Engineering, University of Minho \\ Azurém Campus, 4800-058, Guimarães, Portugal \\ \{nunomendes,pbl\}@civil.uminho.pt
}

Keywords: Masonry, Ancient Buildings, Earthquake, Seismic Performance.

\begin{abstract}
Ancient masonry structures are usually associated to a high seismic vulnerability, mainly due to the properties of the materials (low tensile and moderate shear strengths), weak connections between floors and load-bearing walls, high mass of the masonry walls and flexibility of the floors. For these reasons, the seismic performance of traditional masonry structures has received much attention in the last decades.

This paper presents the sensitivity analysis taking into account the deviations on features of the "gaioleiro" buildings - Portuguese building typology. The main objective of the sensitivity analysis is to compare the seismic performance of the structure as a function of the variations of its properties with respect to the response of a reference model. The sensitivity analysis was carried out for two types of structural analysis, namely for the non-linear dynamic analysis with time integration and for the pushover analysis proportional to the mass of the structure. The Young's modulus of the masonry walls, Young's modulus of the timber floors, the compressive and tensile non-linear properties (strength and fracture energy) were the properties considered in both type of analysis. Additionally, in the dynamic analysis, the influences of the viscous damping and of the vertical component of the earthquake were evaluated. Finally, a pushover analysis proportional to the modal displacement of the first mode in each direction was also carried out.

The results shows that the Young's modulus of the masonry walls, the Young's modulus of the timber floors and the compressive non-linear properties are the parameters that most influence the seismic performance of the structure for both sensitivity analyses. Furthermore, it is concluded that that the stiffness of the floors influences significantly the strength capacity and the collapse mechanism of the numerical model, and the strengthening of the timber floors improved significantly the seismic performance of the ancient masonry buildings with flexible floors.
\end{abstract}




\section{INTRODUCTION}

The seismic behavior of ancient masonry buildings is particularly difficult to characterize and depends on several factors, namely the material properties, the geometry of the structure, the foundations, the connections between walls and floors, the connections between walls and roof, the stiffness of the horizontal diaphragms and the building condition. Furthermore, the strength of "non-structural" elements (partition walls) and their connection to the load-bearing walls also contribute for the performance of ancient masonry buildings.

Masonry is a composite material that consists of units and mortar, which has been used for construction of housing and some of the most important monuments around the world. Units are such as bricks, blocks, ashlars, irregular stones and others. Mortar can be clay, bitumen, chalk, lime/cement based mortar, glue or other. The huge number of possible combinations generated by the geometry, nature and arrangement of units as well as the characteristics of the joints raises doubts about the accuracy of the term masonry.

The strength of masonry depends on the unit and mortar properties as well as on the construction technique. The compressive strength of the units may range from $5 \mathrm{MPa}$ (limestone units of low quality) to over $130 \mathrm{MPa}$ (limestone units of good quality). The strength of the mortar also presents high deviations and depends on the proportion of its components (cement, lime, sand and water) used in the mix [1]. The compressive strength of the mortar of ancient masonry buildings ranges from 1.5 MPa to 3.5 $\mathrm{MPa}[2,3]$. Furthermore, the strength and failure modes of the masonry are also dependent on the loading direction and combination of the loads [4]. Nevertheless, the mechanical behavior of different types of masonry has some common features: high specific mass, low tensile strength, low to moderate shear strength and low ductility (quasi-brittle behavior). The specific mass of stone masonry ranges between $1700 \mathrm{~kg} / \mathrm{m}^{3}$ to $2200 \mathrm{~kg} / \mathrm{m}^{3}$ [5].

The features of masonry allow it to be a material mainly for structural elements under compressive stresses caused by vertical static loads (e.g. walls, arches, vaults and columns subject to the self-weight). Masonry properties have direct influence on the seismic performance of unreinforced masonry buildings, therefore, this material has been considered unsuitable for the construction of buildings in seismic zones. The inertial forces induce tensile and shear stresses which may lead to the failure of masonry elements and, consequently, to local or global collapse of the building. More information about the mechanical behavior of the masonry is given in $[1,4,6]$.

The in-plane and in-elevation regularity as well as simplicity (geometry, mass and stiffness distribution) are aspects that improve the seismic performance of masonry structures, preventing local damage and decreasing the torsional effects. These criteria as well as a set of material properties requirements, design and detailing rules are present in modern codes $[7,8$, 9], which aim at a good seismic performance of masonry buildings in terms of strength capacity and adequate collapse mechanisms. However, ancient masonry buildings were not built according to any particular code and a great number of unreinforced masonry buildings subjected to earthquakes presented serious damage or even total collapse.

Existing masonry buildings present several types of geometry and material properties, which may lead to different damage and collapse mechanisms. However, the types of damage generally occurring in unreinforced masonry buildings due to the seismic action are [6]:

- Cracks between walls and floors;

- Cracks at the corners and at wall intersections;

- Out-of-plane collapse of the perimetral walls;

- Cracks in spandrels beams and/or parapets;

- Diagonal cracks in structural walls; 
- Partial disintegration or collapse of structural walls;

- Partial or complete collapse of the buildings.

For more information about the damage occurring in unreinforced masonry buildings see e.g. $[10,11]$.

Although the seismic performance of unreinforced masonry buildings depends on several aspects, only the seismic behaviour of the masonry walls and of the floors are discussed next.

The in-plane behaviour of masonry walls depends on the geometry of piers, spandrels and openings. In what concerns the seismic behaviour of piers, the typical in-plane collapse mechanisms (Figure 1) are $[12,13]$ :

- Rocking: the high bending causes horizontal cracks at the top and at the bottom of the pier. The failure of the pier occurs by overturning of the wall;

- Sliding: when the horizontal forces at the piers are larger than the shear strength of the bed joints (low vertical load and low friction coefficient), where horizontal cracks develop and the pier presents sliding movement along the bed joints;

- Diagonal tension: the principal tensile stress caused by the seismic action exceeds the tensile strength of masonry and the pier presents diagonal cracks. The cracks can propagate along the mortar bed joints and head joints or go through the units, depending on the strength of the mortar, mortar-unit interface and unit;

- Toe crushing: the toes of the piers are usually zones of high compressive stresses and when the principal compressive stress caused by the seismic action exceeds the compressive strength of the masonry a compressive failure (crushing) can occur.

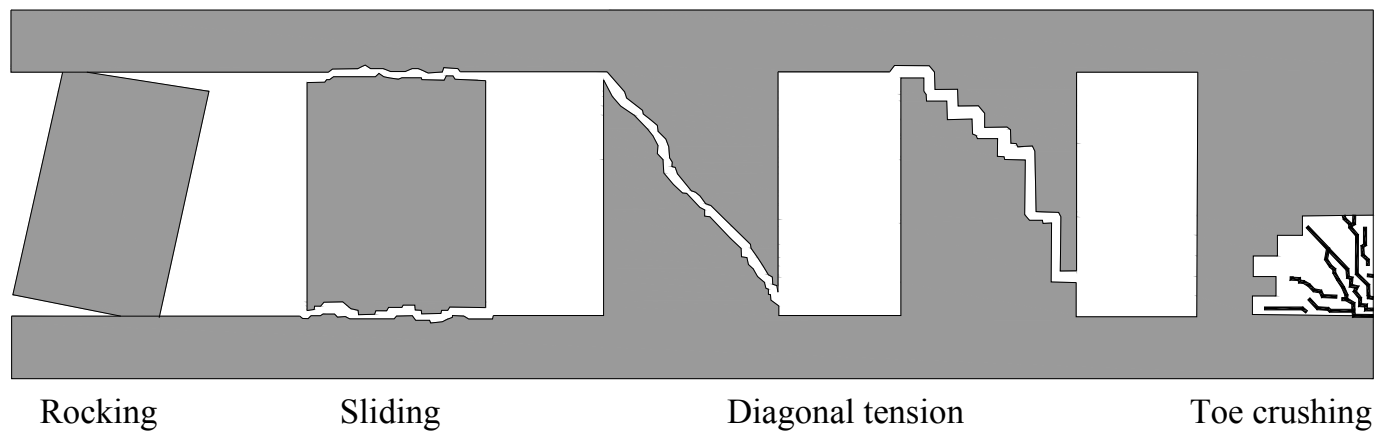

Figure 1: In-plane collapse mechanisms of the piers (adapted from [13]).

The behaviour of spandrels is similar to the behaviour of piers. However, two aspects have to be taking into account: (a) the axis of the spandrel is horizontal and not vertical as in the piers; (b) the normal stress existing in the spandrels, caused by vertical loads, is significant lower than the one in the piers. The first aspect is important for regular masonry, due to orthotropic behaviour, while irregular masonry presents, in general, isotropic behaviour, independent from the load direction. The second aspect has consequences in both types of masonry, as the normal stress influences the seismic behaviour of spandrels. Figure 2a presents the in-plane behaviour of the spandrels subjected to a seismic action, in which shear stresses initially occur and can lead to them to collapse (Figure 2b). In masonry buildings with reinforced elements that prevent such collapse mechanisms (Figure 2c), diagonal compression occurs and this increases the bending strength of the spandrel. In these conditions, the spandrels present two possible collapse mechanisms [14]: 
- Collapse due to high compression of diagonal strut (similar to the collapse for combined axial and bending forces of a pier);

- Collapse due to diagonal tension (shear failure).

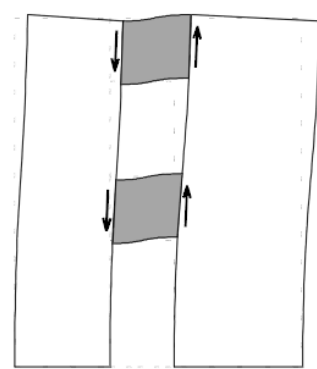

(a)

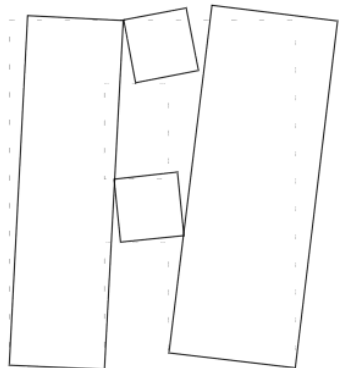

(b)
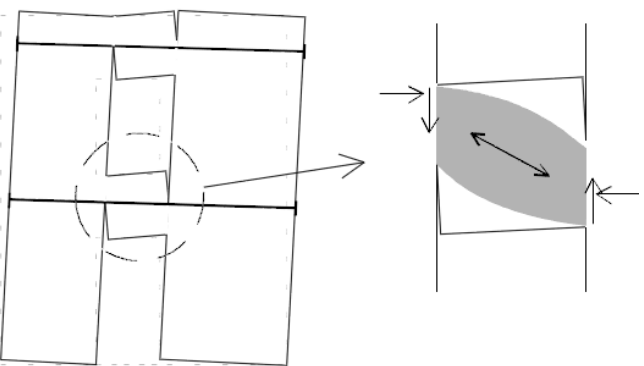

(c)

Figure 2: In-plane behaviour of the spandrels [14].

The out-of-plane behavior of unreinforced walls is complex and depends on the connection between walls and floors, the connection between walls and roof, and the in-plane stiffness of the floors. When the floors are rigid and have sufficient strength, masonry walls have local effects. On the other hand, when the floors are flexible or the connection between the walls and the floors is weak, the walls present a global behavior (independent of the floor levels) with collapses involving one or more floors and, consequently, present lower stiffness and strength [15].

Diaphragms distribute the inertial forces to the building's vertical resisting elements. The distribution capacity of lateral loads through the diaphragms is dependent on the in-plane stiffness of the diaphragms and on the connection between walls and diaphragms. In contrast to a rigid diaphragm, in which the in-plane stiffness is so large that the distribution among the vertical elements is affected only by the location and lateral stiffness of these structural elements, a flexible diaphragm (timber floors) usually exhibits significant bending and shear deformations under horizontal loads, influencing the distribution of the load among the elements of the structure. The importance of the flexibility of the floor diaphragms and of the connections between these and the masonry walls plays an important role in the global and local response of masonry buildings under seismic load.

This works presents the sensitivity analysis taking into account the deviations on features of the ancient masonry buildings. The main objective of the sensitivity analysis is to compare the response of the structure as a function of the variations of its properties with respect to the response of a reference numerical model. The sensitivity analysis was carried out for two types of structural analysis, namely for the non-linear dynamic analysis with time integration and for the pushover analysis.

\section{REFERENCE NUMERICAL MODEL}

\subsection{Preparation of the reference numerical model}

The definition of a reference numerical model was the first step of the sensitivity analysis. The numerical model is representative of a Portuguese masonry building typology - gaioleiro buildings [16] and is based on mock-up tested in the 3D shaking table of the National Laboratory for Civil Engineering (LNEC) in Lisbon [17]. The mock-up has four floors, two facades with openings, two gable walls without openings, and timber floors. In the construction of the timber floors, medium-density fibreboard (MDF) panels, with thickness 
equal to $0.012 \mathrm{~m}$, connected to a set of timber joists spanning in the direction of the shortest span, were used. The reference numerical model (Figure 3a) was prepared using the Finite Element Method (FEM) and the non-linear analysis software DIANA [18], in which quadratic shell elements with eight nodes (CQ40S) were used for simulating the masonry walls and beam elements with three nodes (CL18B) were used for simulating the MDF panels and the timber joists [18]. All the finite elements are based on the theory of Mindlin-Reissner, in which the shear deformation is taken into account. In the modelling of the floors, shell elements were used aiming at simulating the in-plane deformability (Figure 3b). The thickness of the masonry walls and of the MDF panels is equal to $0.510 \mathrm{~m}$ and $0.036 \mathrm{~m}$, respectively, and the dimensions of the cross section of the timber joists are equal to $0.300 \times 0.225 \mathrm{~m}^{2}$ (width and height), with spacing of $1.05 \mathrm{~m}$. In plan, the numerical model has $9.45 \times 12.45 \mathrm{~m}^{2}$ and the interstory height is equal to $3.60 \mathrm{~m}$. The translation and rotation degrees of freedom at the base were restrained. In what concerns the connections, tyings providing equal translation of degrees of freedom between walls and floors were assumed. The numerical model involves 5,816 elements ( 1,080 beam elements and 4,736 shell elements) with 15,176 nodes, resulting in 75,880 degrees of freedom.

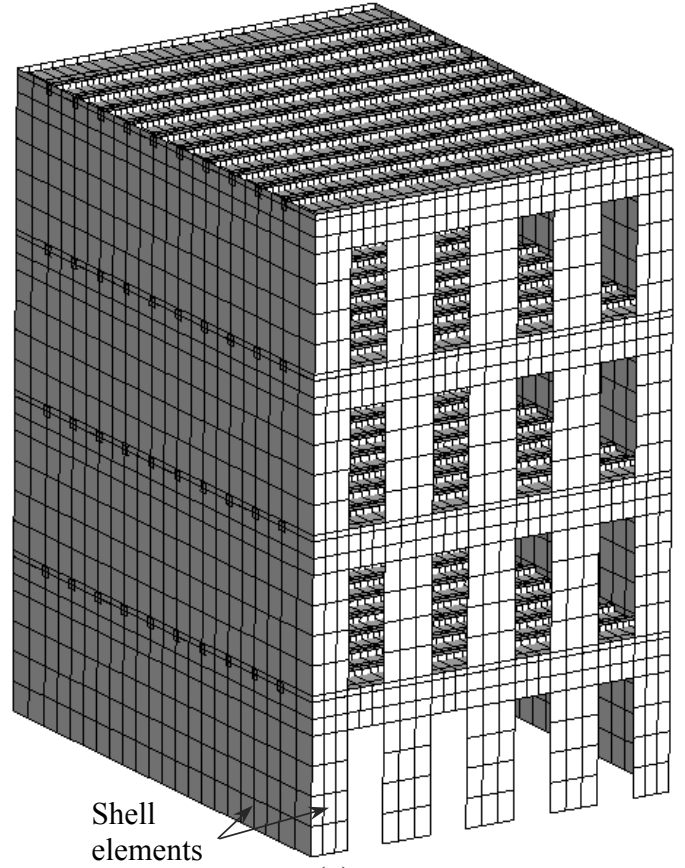

(a)

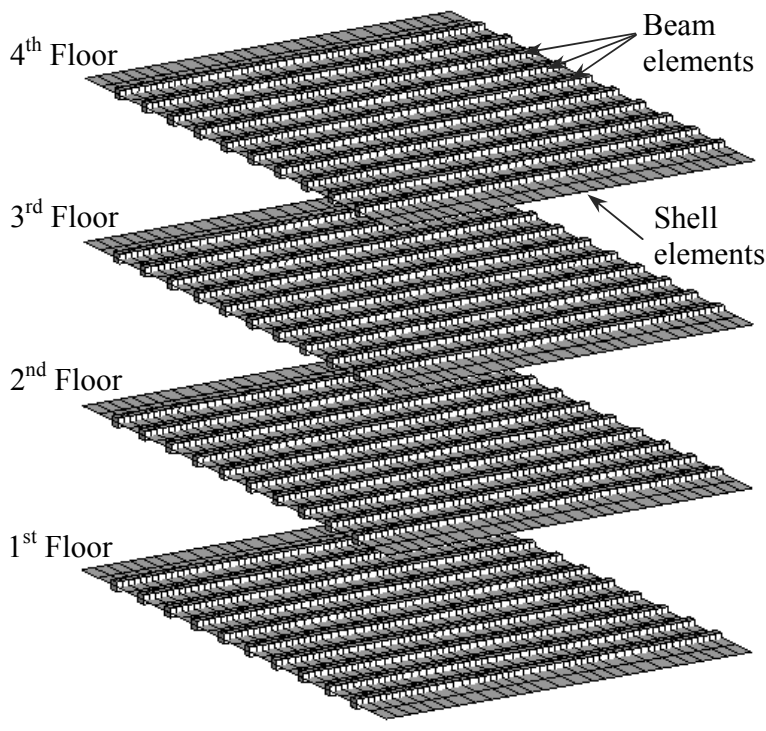

(b)

Figure 3: Numerical model: (a) general view; (b) detail of the floors.

The selection of the masonry constitutive model was based on a compromise between accuracy of the results and computation time. The Total Strain Fixed Crack Model [18], which corresponds to a model of distributed and fixed cracks based on total strains, was selected due to its robustness and simplicity. In this model, the cracks are fixed according the principal directions of the strains and remain invariant during the loading of the structure. Several stress-strains relationships were used. Here, and taking into account that only the nonlinear behaviour of the masonry was considered, exponential tension-softening for the tensile behaviour and parabolic hardening and softening for the compressive behaviour were adopted. The shear behaviour was simulated by a linear relationship between stress and strains, in which the shear stiffness is reduced after cracking according to the following equation: 


$$
G^{c r}=\beta G
$$

where $G^{c r}$ is the shear modulus after cracking, $G$ is shear modulus without damage and $\beta$ is the shear retention factor (ranging from zero to one).

The crack bandwidth $h$ for the shell elements was estimated as function of the area of the element $A$, making the analysis results independent of the size of the finite element mesh:

$$
h=\sqrt{A}
$$

Table 1 and Table 2 present the linear and non-linear material properties of the reference numerical model, respectively.

\begin{tabular}{llll}
\hline & Young's modulus [GPa] & Specific mass $\left[\mathrm{kg} / \mathrm{m}^{3}\right]$ & Poisson ratio \\
\hline Masonry walls & 1.00 & 2162 & 0.2 \\
MDF panels & 0.16 & 760 & 0.3 \\
Timber joists & 12.00 & 580 & 0.3 \\
\hline
\end{tabular}

Table 1: Linear material properties of the reference model.

\begin{tabular}{lllll}
\hline & $\begin{array}{l}\text { Compressive strength } \\
f_{c}[\mathrm{MPa}]\end{array}$ & $\begin{array}{l}\text { Compressive fracture } \\
\text { energy } G_{c}[\mathrm{~N} / \mathrm{mm}]\end{array}$ & $\begin{array}{l}\text { Tensile strength } \\
f_{t}[\mathrm{MPa}]\end{array}$ & $\begin{array}{l}\text { Mode I- tensile fracture } \\
\text { energy } G_{t}[\mathrm{~N} / \mathrm{mm}]\end{array}$ \\
\hline Masonry walls & 1.00 & 1.60 & 0.10 & 0.05 \\
\hline
\end{tabular}

Table 2: Non-linear material properties of the masonry walls of the reference model.

In what concerns damping for the non-linear dynamic analysis, the $\underline{C}$ viscous damping (proportional to the velocity) of Rayleigh was adopted, which is a linear combination between the mass and stiffness matrix in the form [19]:

$$
\underline{C}=\alpha \underline{M}+\beta \underline{K}
$$

where $\alpha$ and $\beta$ are the coefficients that weigh the contribution of the mass $\underline{M}$ and $\underline{K}$ matrices, respectively. The $\alpha(1.48218)$ and $\beta(0.00052)$ were determined through the damping ratios identified in the dynamic identification tests carried out at LNEC.

\subsection{Seismic performance of the reference numerical model}

Non-linear dynamic analysis with time integration and pushover analyses proportional to the mass were carried out. In the dynamic analysis, two artificial accelerograms were applied in two uncorrelated orthogonal directions (Earthquake 100\%). The accelerograms were generated based on stochastic methods and techniques of finite fault modelling, with parameters adequate for Portugal [20] and duration equal to $30 \mathrm{~s}$ (intense phase). The response spectrum of the accelerograms is compatible with the type 1 design response spectrum defined by Eurocode 8 [7] and Portuguese National Annex for Lisbon $\left(P G A=1.5 \mathrm{~m} / \mathrm{s}^{2}\right)$, with a damping ratio equal to $5 \%$ and a type $A$ soil (rock, $\left.S=1\right)$. The pushover analysis is a non-linear static analysis that aims at simulating the structural response during an earthquake, through application of incremental horizontal forces (forced based) or displacements (displacement based) until collapse. The response of the structure is given by the so-called capacity curve, which represents the value of the base shear or seismic coefficient (Equation 4) versus the displacement at a control point (usually at the top of the structure). 


$$
\alpha_{b}=\frac{\sum \text { Horizontal forces at the base }}{\text { Self }- \text { weight of the structure }}
$$

In the non-linear dynamic analysis with Earthquake $100 \%$, the maximum seismic coefficient at the base is equal to 0.10 and 0.25 in the transversal and longitudinal direction, respectively (Figure 4). According to the pushover analyses, the force based capacity reaches its limit in the transversal direction $\left(\alpha_{b}=0.10\right)$. However, in the longitudinal direction the seismic coefficient obtained from the non-linear dynamic analysis $\left(\alpha_{b}=0.25\right)$ is significantly lower than the force based capacity obtained from the pushover analysis $\left(\alpha_{b}=0.46\right)$. Furthermore, in the non-linear dynamic analysis the displacement is significantly lower than the value obtained from the pushover analysis. As an example, in the transversal direction the maximum displacement at the top obtained from the non-linear dynamic analysis (Earthquake $100 \%$ ) and from the pushover analysis is about $4.4 \mathrm{~cm}$ and $20.0 \mathrm{~cm}$, respectively, which corresponds a difference of about $355 \%$. Thus, the seismic action was increased and a nonlinear dynamic analysis with Earthquake $300 \%$ was carried out, aiming at exploring the deformation capacity of the structure and obtaining serious damage that allows identifying clearly the collapse mechanism. In the non-linear dynamic analysis of the Earthquake $300 \%$ (Figure 4), the force based capacity approaches the one obtained from the pushover analyses. In terms of deformation, in the transversal direction the non-linear dynamic analysis of the Earthquake $300 \%$ presents similar maximum displacement at the top. However, in the longitudinal direction the analyses present significant differences.

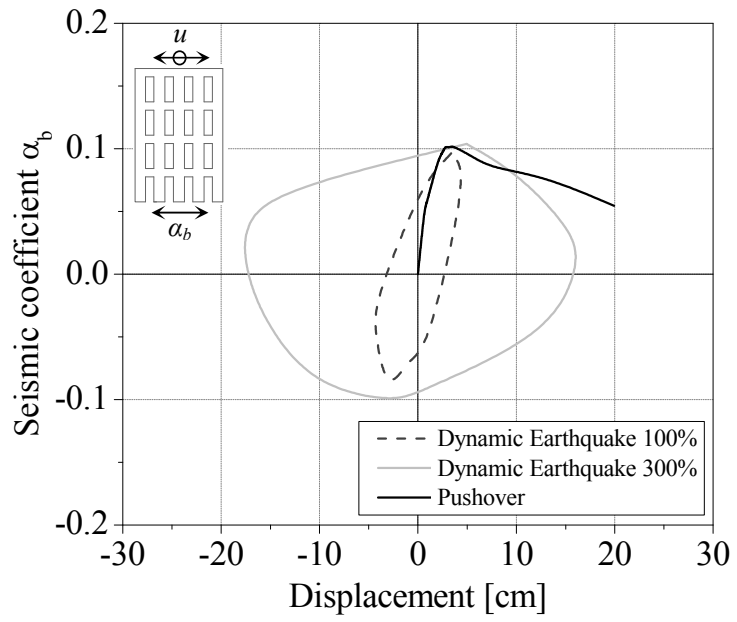

(a)

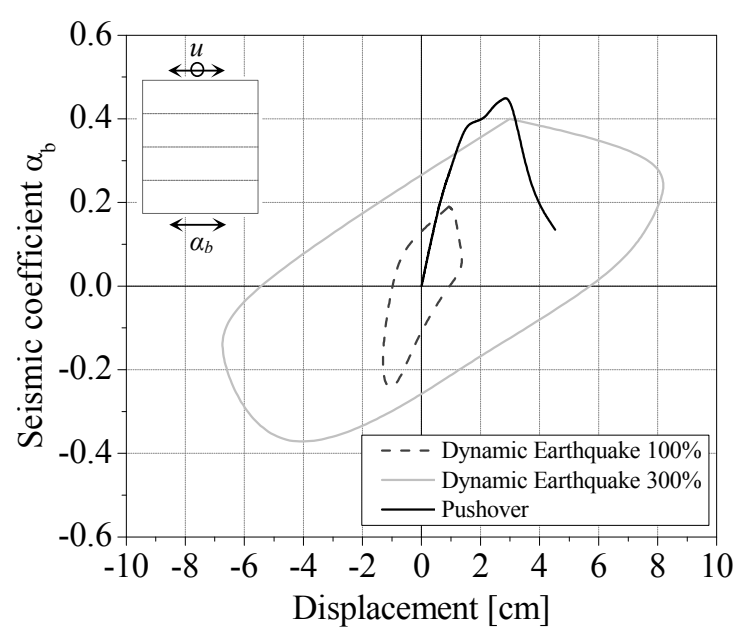

(b)

Figure 4: Envelope of the response obtained from the non-linear dynamic analysis with time integration and capacity curve obtained from the pushover analysis of the reference model in the: (a) transversal direction;

(b) longitudinal direction.

Figure 5a presents the distribution of the maximum principal tensile strains, which is an indicator of the cracking, for the non-linear dynamic analysis of the Earthquake $100 \%$. It is observed that damage concentrates at the spandrels, due to the diagonal cracking, and at the piers of the top floor, due to in-plane rocking and out-of-plane bending. The gable walls do not present significant damage. In the Earthquake 300\% (Figure 5b) the structure presents serious damage, with several spandrels totally damaged and piers at the top floor presenting significant cracks due to in-plane rocking and out-of-plane bending. Furthermore, the piers of the first floor also present severe damage. This damage is related to the damage of the 
spandrels, which present significant deformations and do not adequately restrict the relative displacements of the piers, causing damage mainly due to in-plane forces. The gables walls also present damage, with shear cracks, which have origin at the floor levels and progress to the middle of the walls, and vertical cracks at the top of the walls. Furthermore, local damage at the base and at the connections between the gable walls and the joists of the first floor is observed.

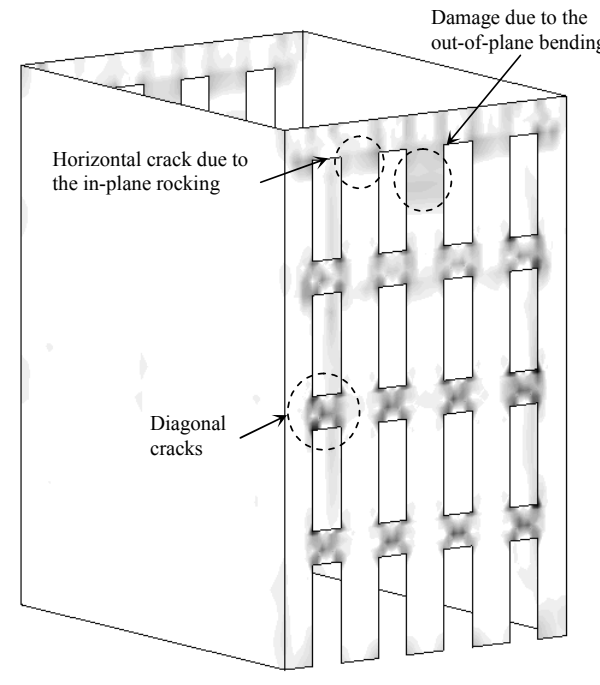

(a)

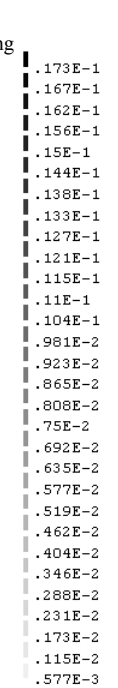

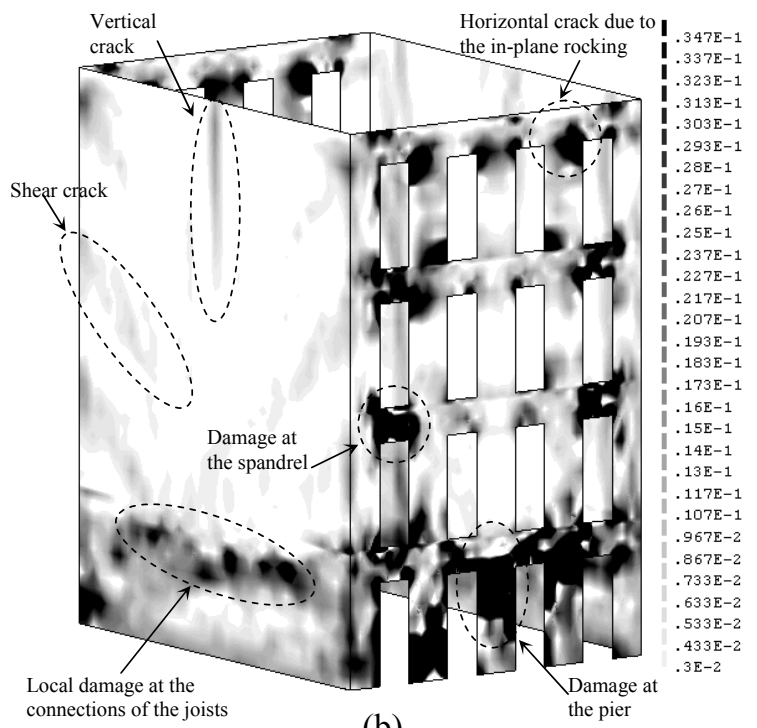

(b)

Figure 5: Maximum tensile principal strains at the external surface of the non-linear dynamic analyses of the reference model: (a) Earthquake 100\%; (b) Earthquake 300\%.

Figure 6 presents the maximum principal strains obtained in the pushover analysis in the transversal and longitudinal direction. The transverse damage (Figure 6a) is according to the one observed in the non-linear dynamic analysis caused by the in-plane forces (Figure 5b), mainly with damage concentration at the piers and horizontal cracks at the piers of the top floor. The piers of the first floor and the base also present damage, but less severe in comparison to the damage observed in the non-linear dynamic analysis. In the pushover analysis in the longitudinal direction (Figure 6b) the piers of the top floor do not presents significant damage caused by the out-of-plane bending as observed in the non-linear dynamic analyses (Figure 5). The damage concentrates mainly in the gable walls, with two vertical shear cracks that have origin at the floor levels and progress to the middle of the base, and one vertical crack. According to this analysis, the numerical model presents a typical collapse mechanism, in which the facades collapse with the vertical cracks occurring at the top floors of the gable walls (near to first joist of the timber floors) and at the corner of the first floor. The MDF panels are rather flexible and are not able to transfer the inertial forces of the facades to the gables, resulting in out-of-plane collapse of the facades. This collapse mechanism is not observed in the non-linear dynamic analysis, because the model reaches its strength capacity firstly in the transversal direction. 


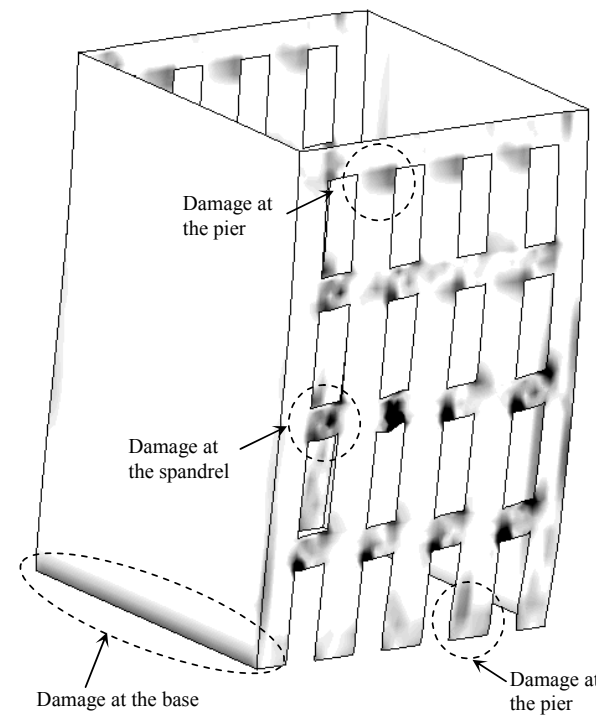

(a)

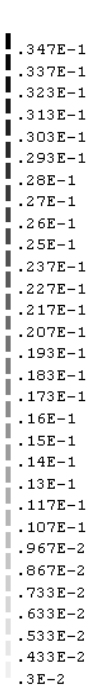

$.3 \mathrm{E}-2$

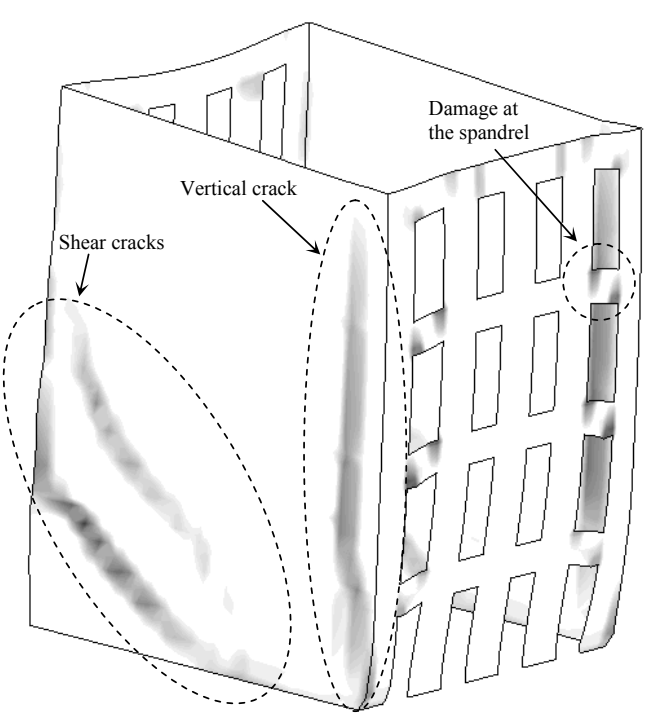

(b)

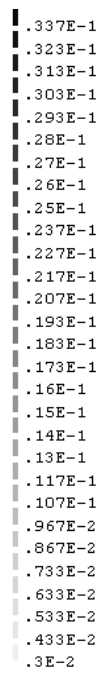

$3 \mathrm{E}-2$

Figure 6: Maximum tensile principal strains at the external surface of the pushover analysis of the reference model in the: (a) transversal direction; (b) longitudinal direction.

\section{NON-LINEAR DYNAMIC SENSITIVITY ANALYSIS}

The non-linear dynamic analysis with time integration involves several parameters that influence the response in a different way and, consequently, the conclusions about the seismic performance of the structures. Thus, a sensitivity analysis taking into account the main parameters that can influence the seismic behavior of the "gaioleiro" buildings was carried out. Here, the objective is to evaluate the variation of response of the structure, with respect to the reference model, varying the value of each parameter, taking into account the dispersion in the features of the "gaioleiro" building typology. The considered parameters (Table 3) aim at evaluating the response of the numerical models with respect to the variation on stiffness of the masonry walls, on stiffness of the floors, on non-linear properties of the masonry in compression and tension, and on damping ratio. Furthermore, the influence in the response of the vertical component of the earthquake was also studied. Next, the main results of the nonlinear dynamic sensitivity analysis (Earthquake 300\%) are briefly presented.

\begin{tabular}{|c|c|c|c|}
\hline & Lower value & Reference value & Upper value \\
\hline Young's modulus of the walls & $0.5 \times E_{\text {walls,ref }}$ & $E_{\text {walls,ref }}=1.00 \mathrm{GPa}$ & $2.0 \mathrm{x} E_{\text {walls,ref }}$ \\
\hline Young's modulus of the floors & $0.1 \times E_{\text {floors }, \text { ref }}$ & $E_{\text {floors }, \text { ref }}=0.16 \mathrm{GPa}$ & $10 \mathrm{x} E_{\text {floors }, \text { ref }}$ \\
\hline Compressive strength & $0.5 \times f_{c, r e f}$ & $f_{c, r e f}=1.00 \mathrm{MPa}$ & $2.0 \times f_{c, r e f}$ \\
\hline Compressive fracture energy & $0.5 \times G_{c, r e f}$ & $G_{c, r e f}=1.00 \mathrm{~N} / \mathrm{mm}$ & $2.0 \times G_{c, r e f}$ \\
\hline Tensile strength & $0.5 \times f_{t, r e f}$ & $f_{t, r e f}=0.10 \mathrm{MPa}$ & $2.0 \times f_{t, r e f}$ \\
\hline Tensile fracture energy & $0.5 \times G_{t, r e f}$ & $G_{t, r e f}=0.05 \mathrm{~N} / \mathrm{mm}$ & $2.0 \times G_{t, r e f}$ \\
\hline Damping ratio & $\zeta_{\text {Lower }}=2.0 \%$ & $\zeta_{\text {ref }}=3.3 \%$ & $\zeta_{\text {Upper }}=5.0 \%$ \\
\hline
\end{tabular}

Vertical earthquake vertical component of the earthquake

Table 3: Parameters considered in the non-linear dynamic sensitivity analysis.

The sensitivity analysis carried out through non-linear dynamic analysis with time integration shows that the Young's modulus of the masonry walls, the Young's modulus of the timber floors and the compressive non-linear properties are the parameters that most influence the seismic performance of the structure. The range of variation of the maximum seismic coefficient assuming $0.50 \mathrm{GPa}$ as lower limit (very poor ancient masonry) and 
$2.00 \mathrm{GPa}$ as upper limit for the Young's modulus of the masonry walls is about $54 \%$ of the reference value. The stiffness of the floors has also an important role on the seismic performance of the structure. The numerical model with very flexible floor presents the typical out-of-plane collapse of the facades with portion of the gable walls and damage at the corners. On the other hand, when increasing the stiffness of the floors the damage concentrates at the facades and the gable walls do not present serious damage. Furthermore, the damage is mainly associated to the in-plane forces (Figure 7).

It is expected that the variation of compressive non-linear properties has limited influence in the response of masonry structures, but here a relevant influence in the strength capacity of the structure has been found. This aspect is related to the low reference value of the compressive strength (1.00 $\mathrm{MPa}$ - ancient masonry), the range of the adopted values $(0.50$ $\mathrm{MPa}$ to $2.00 \mathrm{MPa}$ ) and the type of failure mode obtained. It is noted that the maximum compressive stress due to the self-weight is about $20 \%$ of the compressive strength, which would seem reasonable for the stability against vertical loading.

The response presented low variations when the tensile properties were changed, which is associated to the low range of the adopted values $\left(0.05 \mathrm{MPa} \leq f_{t} \leq 0.20 \mathrm{MPa} ; 0.025 \mathrm{~N} / \mathrm{mm} \leq\right.$ $G_{t} \leq 0.100 \mathrm{~N} / \mathrm{mm}$ ). However, these limits correspond to a common feature of masonry - low tensile strength, meaning that the non-linear tensile properties seem not to affect significantly the response under high seismic amplitude.

The response of the structure in the transversal direction does not change significantly decreasing the ratio damping of about $1 \%\left(\zeta_{\text {Lower }}=2.0 \%\right)$. The maximum variation of the response in the longitudinal direction with $\zeta_{\text {Lower }}=2.0 \%$ is equal to $-8 \%$ (displacement at the top). In the transversal direction of the numerical model with $\zeta_{\text {Upper }}=5.0 \%$ the maximum seismic coefficient increases about $10 \%$ and the maximum displacement at the top decreases about $17 \%$. In the longitudinal direction the response $\left(\zeta_{\text {Upper }}=5.0 \%\right)$ presents a variation of about $20 \%$ for both parameters. The numerical model with $\zeta_{\text {Lower }}=2.0 \%$ presents serious damage at the spandrels, piers at the top floor and at the base, and at the first floor of the gable walls. On the other hand, when increasing the damping $\left(\zeta_{\text {Upper }}=5.0 \%\right)$ the numerical model presents, as expected, a damage reduction.
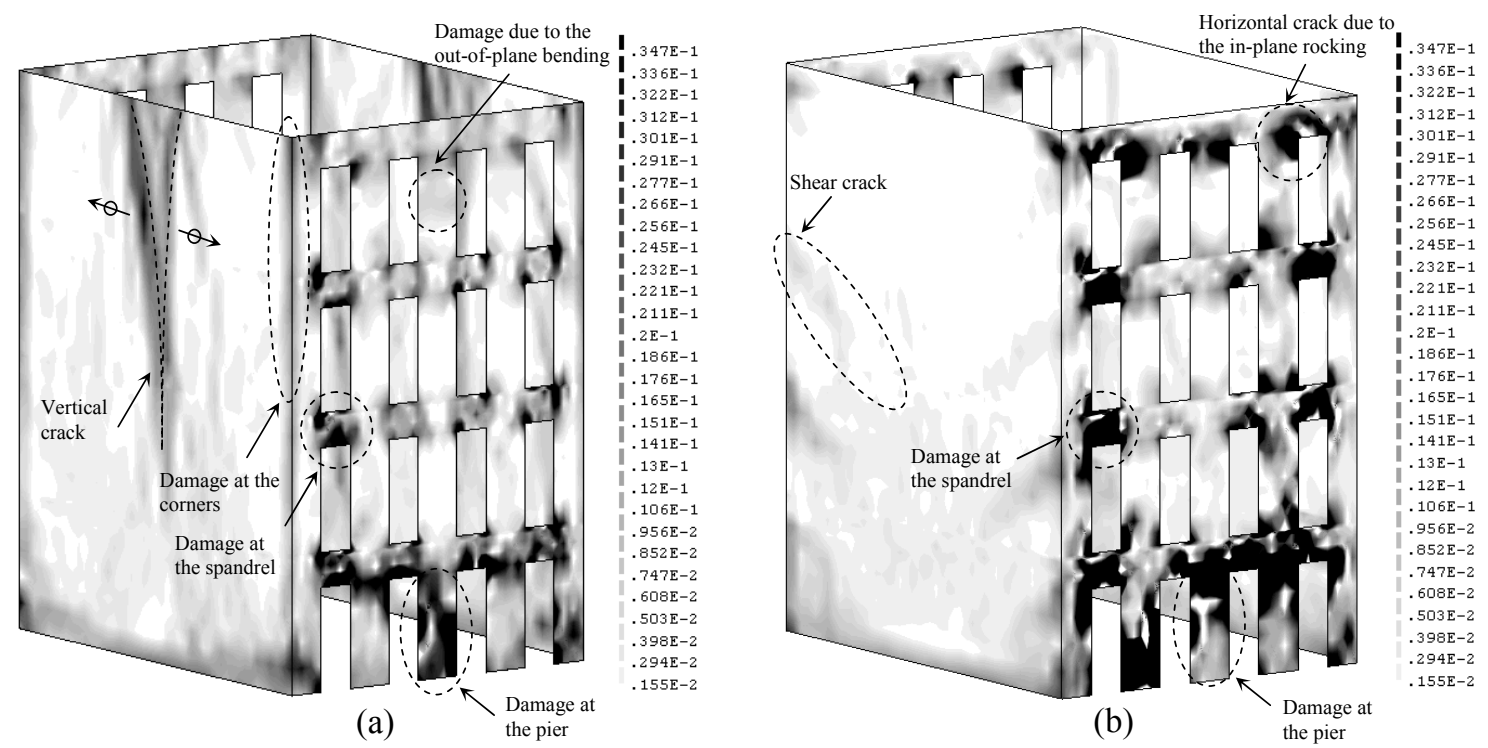

Figure 7: Maximum tensile principal strains at the external surface, obtained from the dynamic analysis, varying the Young's modulus of the floors: (a) $0.1 \times E_{\text {floors, ref }}$; (b) $10 \times E_{\text {floors,ref. }}$. 
The vertical component of the earthquake does not have influence on the response, which is due to the dimensions of the structure and high compressive stresses present, minimizing the effect of the vertical acceleration. Furthermore, the structure is very stiff in the vertical direction and, consequently, presented very small deformation in this direction. Table 4 and Table 5 present the variation of the maximum seismic coefficient and displacement at the top of the structure obtained from the non-linear dynamic parametric analysis for the transversal direction (direction with the lowest strength capacity).

\begin{tabular}{llllllll} 
& $0.5 \times E_{\text {walls, ref }}$ & $0.1 \times E_{\text {floors, ref }}$ & $0.5 \times f_{c, \text { ref }}$ & $0.5 \times G_{c, \text { ref }}$ & $0.5 \times f_{t, \text { ref }}$ & $0.5 \times G_{t, \text { ref }}$ & $\zeta=2 \%$ \\
\hline Seismic coefficient & $-10 \%$ & $10 \%$ & $-20 \%$ & $0 \%$ & $-2 \%$ & $10 \%$ & $0 \%$ \\
Displacement & $-7 \%$ & $24 \%$ & $-16 \%$ & $-11 \%$ & $4 \%$ & $-1 \%$ & $0 \%$ \\
\hline
\end{tabular}

Table 4: Variation of the response in the transversal direction obtained from the non-linear dynamic parametric analysis for the lower limits of the parameters.

\begin{tabular}{lllllllll} 
& $2.0 \times E_{\text {walls, ref }}$ & $10 \times E_{\text {floors, ref }}$ & $2.0 \times f_{c, \text { ref }}$ & $2.0 \times G_{c, \text { ref }}$ & $2.0 \mathrm{x} f_{t, \text { ref }}$ & $2.0 \mathrm{x} G_{t, \text { ref }}$ & $\zeta=5 \%$ & $\begin{array}{l}\text { Vertical } \\
\text { earthquake }\end{array}$ \\
\hline Seismic coefficient & $39 \%$ & $20 \%$ & $70 \%$ & $20 \%$ & $20 \%$ & $10 \%$ & $10 \%$ & $10 \%$ \\
Displacement & $-17 \%$ & $-6 \%$ & $3 \%$ & $3 \%$ & $0 \%$ & $-4 \%$ & $-17 \%$ & $-3 \%$ \\
\hline
\end{tabular}

Table 5: Variation of the response in the transversal direction obtained from the non-linear dynamic parametric analysis for the upper limits of the parameters and earthquake vertical component.

\section{PUSHOVER SENSITIVITY ANALYSIS}

As previously done in the non-linear dynamic sensitivity analysis, in the pushover sensitivity analysis presented next the values of the Young' modulus of the masonry walls, the Young' modulus of the timber floors and the compressive and tensile non-linear properties of the masonry were changed and the variations on the response were analyzed. Furthermore, the type of load pattern applied horizontally to the structure was also discussed and a pushover analysis proportional to the modal displacements of the first mode in the applied direction was carried out besides a standard uniform load distribution (Table 6). Here, the objective is to evaluate the variation of the response of the structure under a seismic action based on displacement (first mode proportional) with respect to a loading based in force (proportional to the mass). Next, the most relevant variations of the response are presented.

\begin{tabular}{llll}
\hline & Lower value & Reference value & Upper value \\
\hline Young's modulus of the walls & $0.5 \times E_{\text {walls,ref }}$ & $E_{\text {walls }, \text { ref }}=1.00 \mathrm{GPa}$ & $2.0 \times E_{\text {walls }, \text { ref }}$ \\
Young's modulus of the floors & $0.1 \times E_{f l o o r s, r e f}$ & $E_{f l o o r s, r e f}=0.16 \mathrm{GPa}$ & $10 \times E_{\text {floors, ref }}$ \\
Compressive strength & $0.5 \times f_{c, \text { ref }}$ & $f_{c, \text { ref }}=1.00 \mathrm{MPa}$ & $2.0 \times f_{c, \text { ref }}$ \\
Compressive fracture energy & $0.5 \times G_{c, \text { ref }}$ & $G_{c, \text { ref }}=1.00 \mathrm{~N} / \mathrm{mm}$ & $2.0 \times G_{c, \text { ref }}$ \\
Tensile strength & $0.5 \times f_{t, r e f}$ & $f_{t, r e f}=0.10 \mathrm{MPa}$ & $2.0 \times f_{t, \text { ref }}$ \\
Tensile fracture energy & $0.5 \times G_{t, r e f}$ & $G_{t, \text { ref }}=0.05 \mathrm{~N} / \mathrm{mm}$ & $2.0 \times G_{t, r e f}$ \\
\hline
\end{tabular}

Load pattern

displacement proportional to the first mode

Table 6: Parameters considered in pushover sensitivity analysis.

The sensitivity analysis based on the pushover proportional to the mass shows that the Young's modulus of the masonry walls, the stiffness of the timber floors and the compressive strength are the properties that present the highest influence on the strength capacity of the structure. Furthermore, the decrease of the tensile strength causes a significant decrease of the strength capacity in the longitudinal direction (-20\%). In the pushover analysis in the transversal direction (direction with the lowest strength capacity) the damage is caused by in- 
plane forces and is similar to the one obtained from the non-linear dynamic analysis, in which severe damage at the spandrels and piers is found.

In the pushover analysis when varying the Young's modulus of the timber floors, the maximum seismic coefficient presents on average variations of about $11 \%$ and $13 \%$ in the transversal and longitudinal direction, respectively (Figure 8). The major differences occur in the pushover analysis in the longitudinal direction, which is more dependent of the stiffness of the timber floors. The numerical model with $10 x E_{\text {floors, }}$ ref presents a response stiffer than the reference model and with a high reduction of the lateral forces after post-peak for low deformation (more brittle behaviour). On the other hand, the response of the numerical model with $0.1 \times E_{\text {floors, ref }}$ presents several losses of stiffness until the maximum seismic coefficient and high deformation (Figure $8 \mathrm{~b}$ ). In the end of the pushover analyses in the longitudinal direction the numerical models with $0.1 \mathrm{x} E_{\text {floors, ref }}$ and $10 \mathrm{x} E_{\text {floors, ref }}$ present similar seismic coefficient and significant different displacements. This is related to the serious damage present in the numerical model with $0.1 \mathrm{x} E_{\text {floors, }}$, mainly due to the vertical crack near the corners that cause the out-of-plane collapse of the facades (Figure 9a). In the numerical model with $10 \mathrm{x} E_{\text {floors, }}$ ref the collapse occurs due to shear failure of the gable walls (Figure $9 \mathrm{~b}$ ).

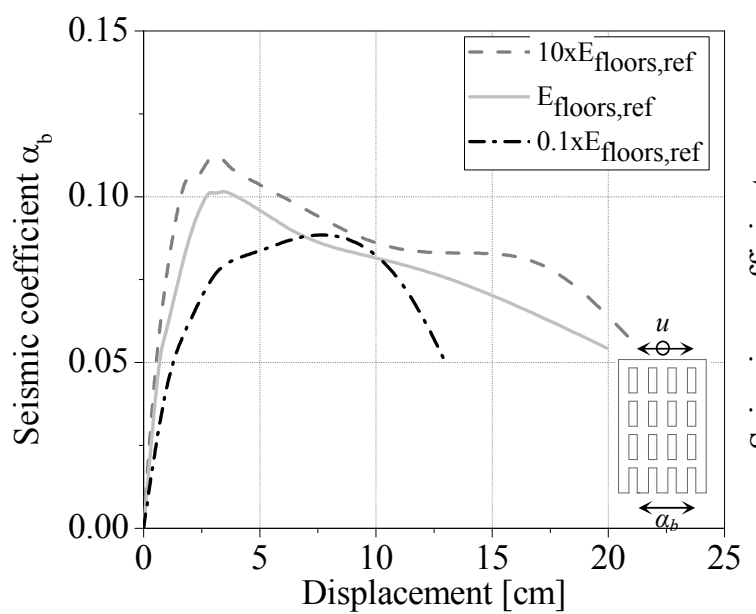

(a)

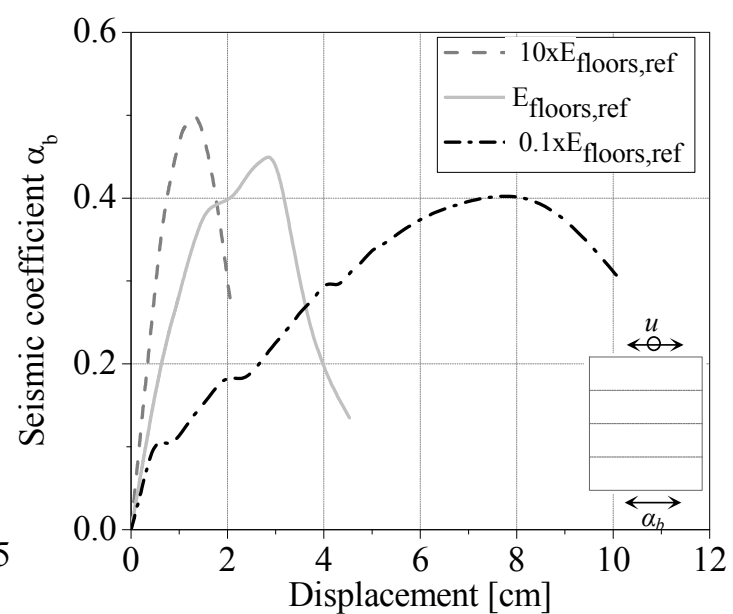

(b)

Figure 8: Capacity curves varying the Young's modulus of the timber floors in the: (a) transversal direction; (b) longitudinal direction.

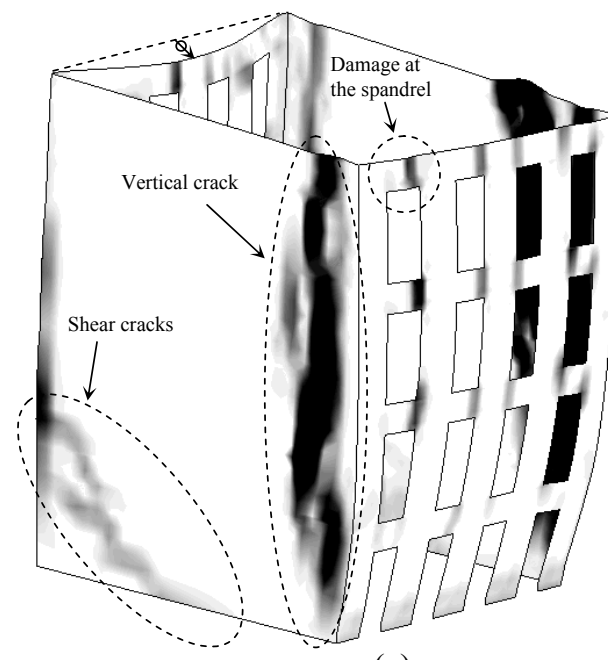

(a)

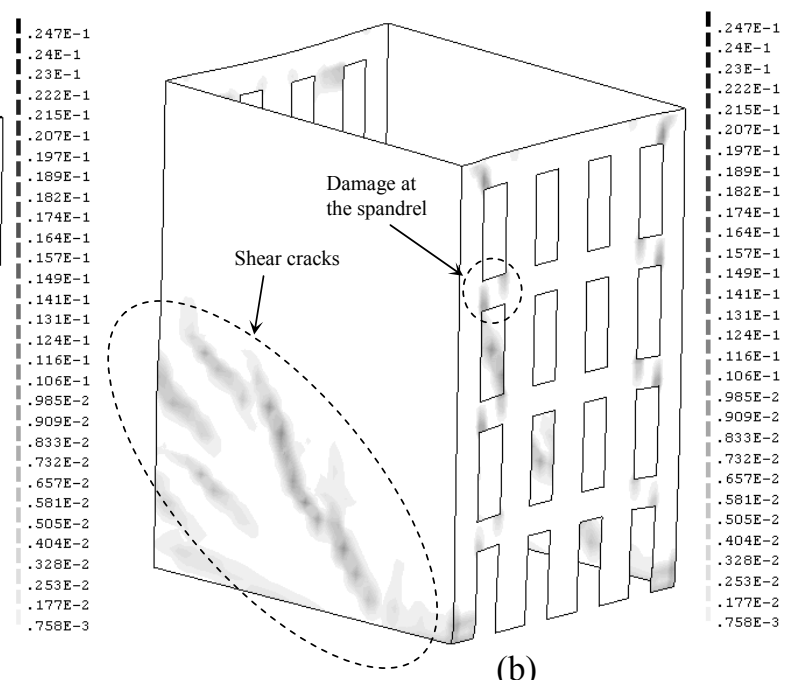

(b)

Figure 9: Maximum tensile principal strains at the external surface, obtained from the pushover analysis in the longitudinal direction, varying the Young's modulus of the floors: (a) $0.1 \mathrm{x} E_{\text {floors, ref }}$; (b) $10 \mathrm{x} E_{\text {floors, ref }}$. 
Finally, the pushover analysis proportional to the modal displacements of the first mode presents lower strength capacity with respect to the pushover analysis proportional to mass and does not provide any improvement in the simulation of the local damage at the piers of the top floor caused by the out-of-plane bending. Table 7 and Table 8 present the variations of the maximum seismic coefficient obtained from the pushover parametric analysis for the transversal and longitudinal directions.

\begin{tabular}{lllllll}
\hline Direction & $0.5 \times E_{\text {walls,ref }}$ & $0.1 \mathrm{x} E_{\text {floors,ref }}$ & $0.5 \mathrm{x} f_{c, \text { ref }}$ & $0.5 \mathrm{x} G_{c, \text { ref }}$ & $0.5 \mathrm{x} f_{t, \text { ref }}$ & $0.5 \mathrm{x} G_{t, r e f}$ \\
\hline Transversal & $-2 \%$ & $-10 \%$ & $-32 \%$ & $-3 \%$ & $-2 \%$ & $-6 \%$ \\
Longitudinal & $-9 \%$ & $-14 \%$ & $-37 \%$ & $-7 \%$ & $-20 \%$ & $-6 \%$ \\
\hline
\end{tabular}

Table 7: Variation of the maximum seismic coefficient obtained from the pushover parametric analysis for the lower limits of the parameters.

\begin{tabular}{llllllll}
\hline Direction & $2.0 \mathrm{x} E_{\text {walls,ref }}$ & $10 \mathrm{x} E_{\text {floors,ref }}$ & $2.0 \mathrm{x} f_{c, \text { ref }}$ & $2.0 \mathrm{x} G_{c, \text { ref }}$ & $2.0 \mathrm{x} f_{t, r e f}$ & $2.0 \mathrm{x} G_{t, \text { ref }}$ & $1^{\text {st }}$ Mode \\
\hline Transversal & $25 \%$ & $11 \%$ & $34 \%$ & $13 \%$ & $11 \%$ & $8 \%$ & $-12 \%$ \\
Longitudinal & $11 \%$ & $12 \%$ & $8 \%$ & $1 \%$ & $8 \%$ & $11 \%$ & $-27 \%$ \\
\hline
\end{tabular}

Table 8: Variation of the maximum seismic coefficient obtained from the pushover parametric analysis for the upper limits of the parameters and pushover analysis proportional to the first mode.

\section{CONCLUSIONS}

A sensitivity analysis using different techniques of structural modelling was carried out, namely: (a) non-linear dynamic analysis with time integration; (b) pushover analysis proportional to the mass. The objective was to evaluate the variation of the response taking into account the deviations in the main features of an ancient masonry building typology of the housing stock of Portugal - gaioleiro buildings.

The Young's modulus of the masonry walls, Young's modulus of the timber floors, the compressive and tensile non-linear properties (strength and fracture energy) were the parameters considered in both type of parametric analysis. Furthermore, in the non-linear dynamic analysis the influence of the variation of the viscous damping and of the vertical component of the earthquake was also evaluated. Finally, a pushover analysis proportional to the modal displacement of the first mode in each direction was carried out. The results of the sensitivity analysis shows that the Young's modulus of the masonry walls, the Young's modulus of the timber floors and the compressive non-linear properties are the parameters that most influence the seismic performance of the structure for both sensitivity analyses. The vertical component of the earthquake does not have influence on the response of the numerical model, which is related to the dimensions of the structure, high compressive stresses caused by self-weight and high stiffness in the vertical direction. The pushover analysis proportional to the modal displacements of the first mode presents lower strength capacity with respect to the pushover analysis proportional to the mass and does not provide any improvement in terms of failure mode.

Finally, it is concluded that the stiffness of the floors influences significantly the strength capacity and the collapse mechanism of the numerical model. Strengthening timber floors such that they can be considered as rigid diaphragms, with good connection between floors and masonry walls, is a solution to reduce the seismic vulnerability of gaioleiro buildings, namely preventing the global collapse of the facades. Here, the strengthening of the floors using timber or steel elements are preferable when compared for example to a solution with concrete slabs, as it allows an increase of the in-plane stiffness of floors without increasing significantly the inertial forces at floor levels. 


\section{ACKNOWLEDGMENT}

The first author sincerely acknowledges the financial support from the Portuguese Foundation for Science and Technology (FCT) through grant SFRH/BD/32190/2006.

\section{REFERENCES}

[1] T. Paulay, M. Priestley, Seismic design of reinforced concrete and masonry buildings. John Wiley \& Sons Inc, 1992.

[2] E. Toumbakari, Lime-pozzolan-cement grouts and their structural effects on composite masonry walls. PhD Thesis, Katholieke Universiteit Leuven, Belgium, 2002.

[3] M. Valluzi, F. Porto, C. Modena, Behaviour and modelling of strengthened three-leaf stone masonry walls. Materials and Structures, 37, No. 3, 184-192, 2004. (doi:10.1007/BF02481618)

[4] P.B. Lourenço, Computational strategies for masonry structures. PhD Thesis, Delft University of Technology, Netherlands, 1996. (Available from: http://www.civil.uminho.pt/masonry)

[5] F. Pinho, Walls from ancient Portuguese buildings. "Edifícios", No8, National Laboratory for Civil Engineering, Lisbon, Portugal, 2000. (In Portuguese)

[6] M. Tomaževič, Earthquake-resistance design of masonry buildings. Series on Innovation in Structures and Construction, Vol. 1. Imperial College Press, 1999.

[7] EN 1998-1, Eurocode 8: Design of structures for earthquake resistance - General rules, seismic actions and rules for building. European Committee for Standardization, 2004.

[8] FEMA 440, Improvement of nonlinear static seismic analysis procedures. Applied Technology Council (ATC-55 Project), Department of Homeland Security, Federal Emergency Management Agency, Washington D.C, 2005.

[9] OPCM 3274, First elements on general criteria for seismic classification of the national territory and technical standards for construction in seismic areas. Ordinance of the President of the Council of Ministers, 2003. (In Italian)

[10] D. D'Ayala, E. Speranza, An integrated procedure for the assessment of seismic vulnerability of historic buildings. $12^{\text {th }}$ European Conference on Earthquake Engineering, London, United Kingdom, paper 561, 2002.

[11] C. Carocci, Guidelines for the safety and preservation of historical centres in seismic areas. Historical Constructions: Possibilities of numerical and experimental techniques, Guimarães, Portugal, 145-166, 2001.

[12] G. Magenes, G. Calvi, In-plane seismic response of brick masonry walls. Earthquake Engineering and Structural Dynamics, 26, Issue 11, 1091-1112, 1997. (doi:10.1002/(SICI)1096-9845(199711)26:11<1091::AIDEQE693>3.0.CO;2-6).

[13] T. Yi, Experimental investigations and numerical simulation of an unreinforced Masonry structure with flexible diaphragms. $\mathrm{PhD}$ Thesis, Georgia Institute of Technology, 2004.

[14] G. Magenes, D. Bolognini, C. Braggio, Simplified methods for non-linear seismic of masonry buildings. National Group for Earthquakes Protection (GNDT), 2000. (In Italian) 
[15] P. Candeias, Seismic vulnerability assessment of ancient buildings. PhD Thesis, University of Minho, Portugal, 2008. (Available from: http://hdl.handle.net/1822/9057) (In Portuguese)

[16] J. Appleton, Rehabilitation of "gaioleiros" buildings - a block in Lisbon. Orion edition, 2005. (ISBN: 9728620055) (In Portuguese).

[17] N. Mendes, P.B. Lourenço, A. Campos-Costa, Seismic vulnerability assessment of ancient masonry building an experimental method. Advanced Materials Research, 134134, 635-640, 2010. (doi: 10.4028/www.scientific.net/AMR.133-134.635)

[18] TNO, DIsplacement method ANAlyser. User's Manual, Release 9.4, Netherlands, 2009.

[19] A. Chopra, Dynamics of Structures: Theory and applications to earthquake engineering, $3^{\text {rd }}$ Edition. Prentice Hall, 2001.

[20] A. Carvalho, Stochastic modelling of the seismic action in Mainland Portugal. $\mathrm{PhD}$ Thesis, Technical University of Lisbon, Portugal, 2007. (In Portuguese). 